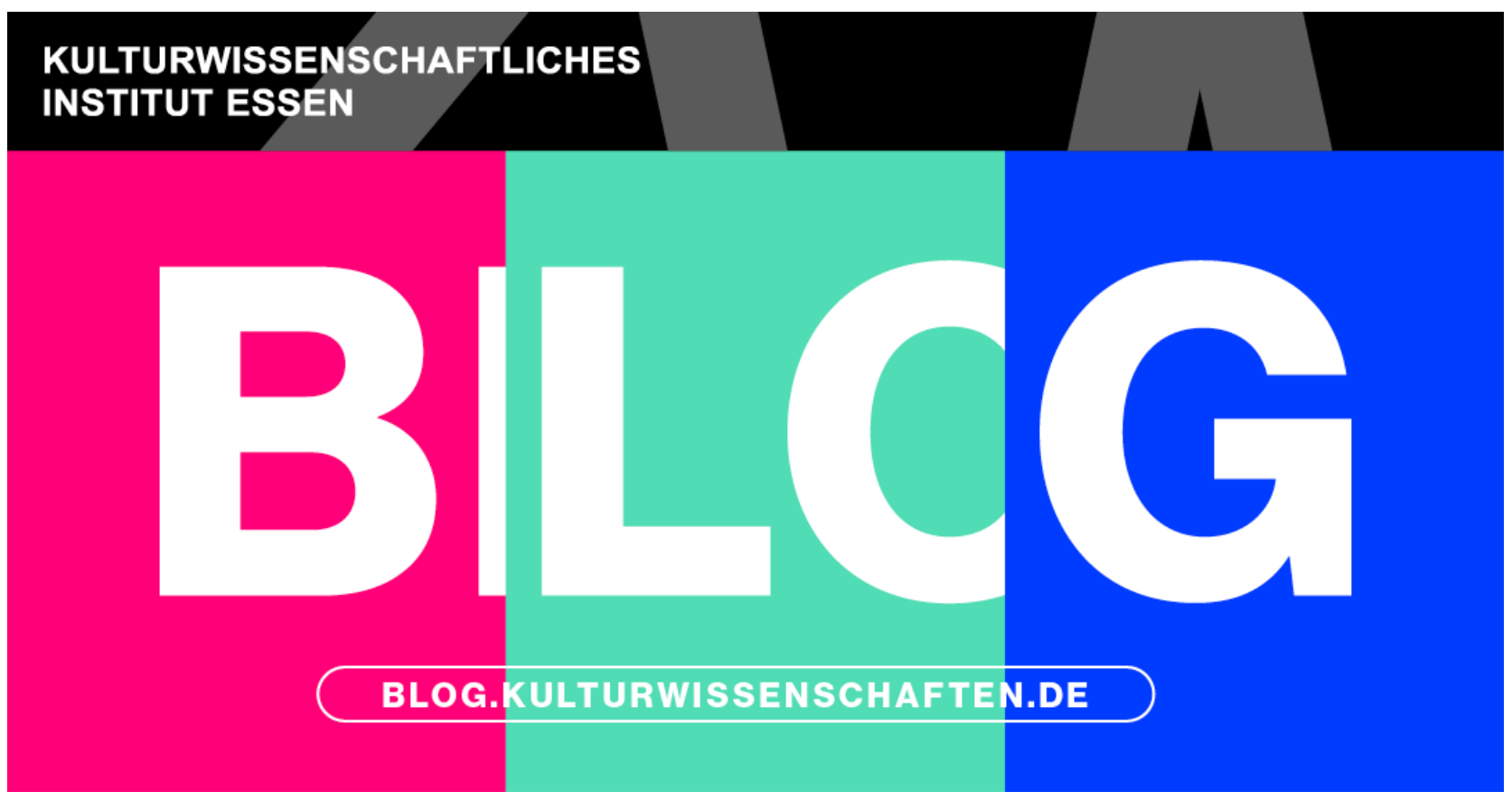

\title{
Die Arbeit der Angst
}

Erschienen in: ANGST + | FEAR +

Von: Jan Wilm

\section{FEAR IS A MAN'S BEST FRIEND • JOHN CALE}

Wovor ich Angst habe und immer Angst gehabt habe: vor der langsam festsickernden Gewissheit der Verzweiflung; vor dem Ausdruck ohne Lächeln oder Liebe in den Gesichtern meiner Lebensmenschen; vor dem Tod meiner Lebensmenschen; vor dem Fliegen; vor dem dunklen Garten vor dem Haus meiner Kindheit; vor dem Haus meiner Kindheit; vor den Blicken auf meinen Körper nach meinem Tod; vor dem Tod; vor dem Sterben; vor dem Wunsch zu sterben.

Wovor ich keine Angst habe, aber einmal Angst hatte: vor Armut; vor Misserfolg; vor dem Scheitern; vor der Scham; vor dem Pathos; vor der Sentimentalität; vor Friedhöfen; vor dem Nutzlosen und Sinnlosen und Bedeutungslosen; vor meiner Erinnerung; vor Gedanken vor dem Einschlafen; vor dem Einschlafen.

Wovor ich keine Angst habe, nie Angst hatte und niemals Angst haben werde: vor dem Schreiben.

Dabei ist das Schreiben für mich in seinem Kern von der Angst berührt. Immer. Doch die abgegriffenen Plattitüden von den Gefahren des Schreibens, von dem horror vacui, von der Angst vor dem leeren Blatt, von der Beschwörung des Terrors durch

Schreibblockaden - all das hat keine Bewandtnis für mein Leben und was damit benannt 
wird keine Herrschaft über meine Gedanken. Schreibende, die das Schreibtischsitzen und Wortausschwitzen in heldischem Getöse in luftige Höhen raufwirbeln, wie Hemingway, der sich den schreibenden Menschen zu einem täglich an die Ewigkeit Ausgelieferten zurechtstilisierte - für derartige Vorstellungen habe ich nur Spott übrig. Allenfalls Mitleid.

Das Schreiben ist die sicherste Tätigkeit, die ich kenne. Gefährlich ist sie nicht, auch wenn von ihr mitunter Zerstörung ausgeht. In meinem Leben, das ein kleines Leben ist und somit ständigen wirklichen Gefahren, ständigen wirklichen Zerstörungen unterworfen, wie jedes andere Leben auch -, in meinem Leben hingegen kann ich mich schützen, indem ich meine Schreibarbeit mache, da sie ihren Ausgang hat in der Angst. Ich schreibe für die Angst, und arbeite mich schreibend mit der Sprache von ihr weg. Ilse Aichinger, die große Angst-Dichterin, bestärkt mich in meinem Schreiben, das aus der Angst heraus entsteht: „Jeden Tag mit Grauen und unabgeschwächter Angst beginnen, kein schlechter Rat." 1

Wenn ich schreibe, besiege ich meine Ängste nicht. Ich benenne sie bloß und banne sie einen Lidschlag lang, artikuliere sie aus meinem Leben heraus, zerstöre sie aus meinem Körper in die Sprache hinein.

Psychologinnen und Psychotherapeuten versuchen seit längerem, mich davon zu überzeugen, dass ich die Angst in meinem Leben nicht brauche, ich solle mich nicht an sie klammern. Manche meinen, ich hätte gar keine Angst, sondern Furcht, da die Angst nicht objektbezogen und nur die Furcht auf etwas Spezielles und Bestimmtes hingeordnet sei. Bislang bin ich standhaft geblieben und ließ mich nicht überzeugen, weil die Worte ,Angst' und ,Furcht' in meinem Gedankengebäude ganz fest miteinander verbaut sind und weil jede konkrete Furcht für mich an eine allgemeine Angst festgeschnürt ist, wie jeder Punkt eines Spinnennetzes verbunden ist mit der Spinne, vor der ich übrigens weder Angst noch Furcht habe.

Im Labyrinth meines Kopfes ist jede Angst ein roter Faden. Folge ich ihm ans Ende, finde ich den Ausgang, doch dieser Ausgang ist das Nichts und also der Tod. Jede kleinste Furcht ist wie ein Vorgeschmack der großen Angst, dass einmal eine ungeheure Masse an Zeit ohne mich stattfinden wird. Die fürchterlichste Wortfolge ist ,nach mir،. Aichinger, abermals: „Manchmal: die Zimmer wie einen Tag nach unserm Tod." 2 In aller Furcht meines Lebens steckt immer auch diese Angst vor der Stille nach mir, die Angst vor dem Tod. Flüchte ich vor kleineren Ängsten, flüchte ich vor der Todesangst, und jeden noch so kleinen Angstmoment nutze ich als Triebkraft fürs Schreiben.

Ein befreundeter Psychologe sagte mir einmal, Angst sei evolutionär ja nichts Schlechtes. Das hochschießende Adrenalin habe beim Kampf gegen Feinde geholfen, die beschleunigte Atmung habe darauf vorbereitet, weglaufen, flüchten zu können. Selbst die auslaufende Blase und der sich entleerende Darm seien prinzipiell als etwas Positives zu betrachten gewesen, weil sich - ich zitiere - „das Startgewicht verringert." Seltsam, dass die sich ins Heroische hochstilisierenden Schreibenden niemals erwähnen, wie wichtig es ist, am Schreibtisch immer gute Unterwäsche zu tragen. 
Ich habe meine eigene Art, am Schreibtisch mit der Angst zu arbeiten. An meiner Wand hängt wie ein Talisman eine herausgerissene Seite aus einem kleinen Pamphlet der Royal Air Force mit dem Titel Arctic Survival, das in den 1950er Jahren an die englischen Piloten der britischen Luftstreitkräfte ausgegeben wurde. Es beinhaltet hilfreiche Tipps fürs Überleben nach einem Flugzeugabsturz in schneedurchwehten Polarregionen. Das Papier an meiner Wand ruft mir jeden Tag Folgendes zu: „Survival depends on two, largely psychological, factors: the determination to live and the elimination of fear. Fear is caused through ignorance, in other words inadequate training."

Ich habe dieses Zettelchen aber nur aus einem einzigen Grund in Blicknähe meines Arbeitsplatzes angebracht. Weil die Person, die das Pamphlet besessen haben muss, bevor ich es in einem Londoner Antiquariat kaufte, diese Worte mit einem dicken roten Wachsmalstift durchgestrichen hat, so dass sie ausgelöscht sind, aber lesbar bleiben. In demselben Wachsmalrot steht im Seitenrand neben den gedruckten Worten in Großbuchstaben: „FUCK NO!“

Die Angst ist für mich kein Hindernis zum Überleben, sondern ein Hilfsmittel. Sie ist Auslöser meines Schreibens, während mein Schreiben eine zeitweilige Auslöschung meiner Angst darstellt, auch wenn sie schwebend dahinzitternd doch irgendwie bestehen bleibt, da ich sonst schließlich meinen Schreibstift beiseitelegen könnte. Schreiben streicht meine Angst - wie mit einem Wachsmalrotstift - dick durch, lässt sie gleichzeitig aber bestehen, als Triebfeder, als mahnender Impuls. Schreibend ist meine Angst gleichzeitig präsent und zerstreut, wie die ausgelöschten Worte in Derridas Sous-ratureVerfahren. Die Angst als Wort, das ich schreibend streiche.

Die Angst steckt in all meinen geschriebenen Dingen. Sie vergrößert Belanglosigkeiten und zeigt mir das Einfache in neuer Weise, und das weiß ich zu schätzen. Auch Montaigne schreibt von der verwunderlichen Verwandlungskraft der Furcht, wie sie Dinge aufblähen lässt, wenn Krieger in einer genüsslich grasenden Schafherde ein bewaffnetes Bataillon zu erkennen glauben. Und auch wenn der nach seinem Schloss benannte alte Eigenbrötler den Phänomenen Furcht und Angst weit weniger Positives abgewinnen kann als Ilse Aichinger und ich, gesteht auch Montaigne zu, dass die Furcht zu „Tapferkeit antreibt“ und zuweilen „unsre Fersen“ beflügelt. ${ }^{3}$

Manchmal hat mir die Angst beim Schreiben derartig Flügel verliehen, dass ich ihr regelrecht dankbar war. Für Aristoteles ist die Tapferkeit, der Mut das Gegenteil von Angst. Für mich ist es das Schreiben, doch zum Schreiben brauche ich keinerlei Mut, keinerlei Tapferkeit. Nie. Das Schreiben ist für mich das Gegenteil der Angst, weil es mich von kopfschmerzgrauen Alltagssorgen löst und paradoxerweise von der Angst wegführt, während die Angst dabei permanent der wichtigste Anstoß bleibt und mich mit dem Wesentlichen in Verbindung bringt, und dieses Wesentliche ist für mich die Frage nach dem Leben im Bewusstsein des Todes, nicht mehr und nicht weniger. Durch die Angst vor dem Tod ist jedes Wort, das ich schreibe, meine Auseinandersetzung mit diesem Wesentlichen. 
„Fear is a man's best friend“, singt John Cale, und auch ich habe mich gut mit ihr arrangiert, sofern ich einen Stift in der Hand halten kann. Schreibend schiebe ich meine Angst davon und schiebe sie auf, lasse mich von ihr durch die Sprache bewegen. Sie trägt mich. Doch an schreiblosen Tagen gehe ich schlafen mit dem Bewusstsein: Heute hat das Sterben gesiegt, heute bin ich lediglich ein wenig näher in den Staub gerückt, der ich einmal sein werde.

„Wovor ich mich am meisten fürchte“, schreibt Montaigne, „ist die Furcht.“4 Franklin D. Roosevelt machte daraus später ein geflügeltes Wort, doch für mich könnte nichts ferner von der Wahrheit sein. In Wahrheit ist für mich das Gegenteil wahrer. Und da liegt's, darin schlummert ein Problem. Denn wovor ich mich eigentlich fürchte, wovor ich eigentlich Angst habe, ist irgendwann einmal keine Angst mehr zu haben, keine Dämonen mehr in mir zu spüren, die mich mit ihren ädrigen Nosferatu-Fingern auch in der dezemberlichsten Morgendunkelheit aus dem warmen Bett zerren, damit ich mich an die Arbeit mache. Ich habe keine Angst, nicht mehr schreiben zu können. Aber ich habe fürchterliche Angst, irgendwann nicht mehr schreiben zu müssen.

Manchmal packt mich diese Angst, lässt mir das Adrenalin und den Puls in den Kopf schießen, beschleunigt meine Atmung und entleert - aber nein, ich muss mir keine Sorgen machen, ich brauche keine Angst zu haben, ich muss mich nicht vor dem Ende der Angst fürchten. Denn der Tag, an dem ich keine Angst mehr vor dem Tod haben werde, wird von mir nicht mehr beschrieben werden, denn es wird der Tag sein, der sich anfühlen wird wie ein Zimmer einen Tag nach meinem Tod. Nach mir. Doch bis es so weit ist, mache ich mich noch ans Schreiben, als liefe ich der feststehenden Zukunft davon, und solang ich noch kann, leiste ich sie ab, meine Arbeit der Angst.

\section{References}

1. Aichinger, Ilse (1987): Kleist, Moos, Fasane, Frankfurt am Main: S. Fischer Verlag, S. 79 .

2. Ebd.: S. 66.

3. Michel de Montaigne (1953/2000): Essais. Aus dem Französischen von Herbert Lüthy, Zürich: Manesse Verlag, S. 117.

4. Ebd.

SUGGESTED CITATION: Wilm, Jan: Die Arbeit der Angst, in: KWI-BLOG, [https://blog.kulturwissenschaften.de/die-arbeit-der-angst/], 02.11.2021

DOI: https://doi.org/10.37189/kwi-blog/20211102-0830 
Dieser Text wird via DuEPublico, dem Dokumenten- und Publikationsserver der Universität Duisburg-Essen, zur Verfügung gestellt. Die hier veröffentlichte Version der E-Publikation kann von einer eventuell ebenfalls veröffentlichten Verlagsversion abweichen.

DOI: $\quad 10.37189 / \mathrm{kwi}-\mathrm{blog} / 20211102-0830$

URN: urn:nbn:de:hbz:464-20211102-110334-6 